\title{
Proto-maya y lingüística diacrónica. Una (breve y necesaria) introducción
}

José Andrés Alonso de la Fuente

\section{(2) OpenEdition \\ Journals}

Edición electrónica

URL: https://journals.openedition.org/jsa/6383

DOI: $10.4000 /$ jsa. 6383

ISSN: 1957-7842

Editor

Société des américanistes

\section{Edición impresa}

Fecha de publicación: 1 diciembre 2007

Paginación: 49-72

ISSN: 0037-9174

\section{Referencia electrónica}

José Andrés Alonso de la Fuente, «Proto-maya y lingüística diacrónica. Una (breve y necesaria)

introducción», Journal de la Société des américanistes [En línea], 93-1 | 2007, Publicado el 15 junio 2012, consultado el 02 septiembre 2022. URL: http://journals.openedition.org/jsa/6383 ; DOI: https:// doi.org/10.4000/jsa.6383 


\title{
PROTO-MAYA Y LINGÜÍSTICA DIACRÓNICA. UNA (BREVE Y NECESARIA) INTRODUCCIÓN
}

\author{
José Andrés ALONSO DE LA FUENTE *
}

\begin{abstract}
El objetivo de este artículo es subrayar la importancia de la lingüística diacrónica y las posibilidades que ésta ofrece desde una perspectiva multidisciplinar. La cooperación con la arqueología y la historia parece ser de hecho especialmente productiva y fructífera, como se demostrará en este estudio. Además, el caso maya es excepcional - único entre las lenguas nativas americanas - dada la antigüedad de los primeros registros escritos y la riqueza de documentos durante la época colonial. [Palabras claves: lingüística diacrónica, filología, lenguas mayas, trabajo multidisciplinar.]
\end{abstract}

Le protomaya et la linguistique diachronique. Une (brève et nécessaire) introduction. Cet article a pour objet de souligner l'importance de la linguistique diachronique et les possibilités qu'elle offre d'un point de vue pluridisciplinaire. De fait, son recoupement avec l'archéologie et l'histoire est tout à fait productif et fructueux. En réalité, le cas maya est exceptionnel - voire unique parmi les langues autochtones d'Amérique - en raison de l'antiquité des premiers registres écrits et de la richesse des documents pendant la période coloniale. [Mots clés: linguistique diachronique, philologie, langues mayas, recherche pluridisciplinaire.]

Proto-Mayan and diachronic linguistics. A (brief and necessary) introduction. The goal of this paper is to underline the importance of the diachronic linguistics and the possibilities which it offers from the interdisciplinary perspective. The co-operation with archaeology and history seems to be specially productive and successful, as it will be show here. In addition, the Mayan case is exceptional, in fact unique among the American native languages, because of its old written records, as well as the richness of documents during the Colonial times. [Key words: diachronic linguistics, philology, Mayan languages, interdisciplinary work.]

* Universidad Complutense de Madrid, departamento de filología clásica y lingüística indoeuropea, Ciudad Universitaria, 28040 Madrid/Universidad del País Vasco, Euskal Herriko Unibertsitatea, Área de filología eslava, facultad de filología y geografia e historia, Paseo de la Universidad, 5 E-01006 Vitoria-Gasteiz [ocitartson@hotmail.com].

Journal de la Société des Américanistes, 2007, 93-1, pp. 49-72. (O) Société des Américanistes. 


\section{INTRODUCCIÓN}

En determinados campos científicos de carácter supuestamente multidisciplinar, el ámbito de la lingüística, en especial de su vertiente diacrónica, casi siempre queda relegado a un segundo plano sin saber ni comprender la razón de tal actitud. La mayística no es, por desgracia, una excepción. La relación genética existente entre las 32 lenguas que conforman la familia lingüistica maya ${ }^{1}$ se conocía - o intuía - hace alrededor de 450 años, cuando comenzaron a ser codificadas. Esos cuatro siglos han servido para corroborar que la lingüística diacrónica maya constituye uno de esos casos privilegiados, incluso a nivel mundial, que no debe, ni puede, ser desaprovechado. El objetivo de este trabajo es presentar un esbozo de la lingüística histórica maya, sobre todo en su faceta práctica, ofreciendo algunos de los numerosos resultados que se han obtenido en conjunción con otras disciplinas como la filología, la arqueología y/o la (pre)historia. Con esto se espera que en un futuro, alentados por la iniciativa convocada en este escrito, varios investigadores promuevan el estudio no solamente de este ámbito de la mayística (porque la « lingüística histórica maya » forma parte de la mayística, no siendo únicamente una cuestión concerniente a la disciplina lingüística), sino de las lenguas nativas americanas en general, haciendo así justicia a la labor emprendida por tantos estudiosos hará casi tres siglos, cuando los medios y las condiciones eran infinitamente peores a las que se presentan en la actualidad ${ }^{2}$.

\section{Falsos PREJUicios}

No son pocos los que, aun siendo especialistas (no lingüistas) en la materia, consideran que las lenguas amerindias son los restos culturales de un grandísimo naufragio del que no se ha conservado prácticamente nada a nivel lingüístico y que por lo tanto el único aspecto que merece algún tipo de atención es el sincrónico por encima del diacrónico ${ }^{3}$. Esto contrasta sin duda alguna con la labor llevada a cabo por los otros especialistas (lingüistas) que decidieron y han decidido dedicarse al estudio de las lenguas amerindias. Es tan prolíica y abundante la bibliografia sobre la lingüística histórica entre las lenguas amerindias que Lyle Campbell (1997b, pp. 429-482), en un increíblemente útil monográfico sobre el tema dedica más de 50 páginas a citar los trabajos más básicos y elementales sobre la cuestión ${ }^{4}$.

En este sentido, el caso de las lenguas mayas es muy especial. La bibliografía relativa a la diacronía de estas lenguas es inmensa, no todo lo que debiera, pero cubre las exigencias mínimas que pueden solicitarse de una gran familia lingüística. Esto ha sido posible no por caprichosos designios del azar, sino porque detrás de todos esos escritos existe una base muy sólida de la que muchos han sabido tomar ventaja. En primer lugar, se dispone de una amplia documentación nativa y no nativa, adaptada a la ortografía castellana, que comienza en el siglo 
Xvi y que continúa hasta nuestros días. Esto constituye sin duda una ventaja de la que no dispone el investigador de otras familias lingüísticas amerindias. Todas y cada una de las lenguas mayas han sido ya objeto de descripciones gramaticales, confección de diccionarios, antologías ${ }^{5}$, etc. A esto deben sumarse las inscripciones jeroglíficas del maya clásico, quese remontanal menos hasta el siglo IIId.C.,y que por el momento reflejan cuatro lenguas distintas: cholano oriental clásico (ancestro del choltí y del ch'orti' modernos), cholano occidental clásico (vinculado al chol y chontal modernos), yucateco clásico (con variedades dialectales que probablemente están indicando las formas antiguas del yucateco por un lado y del itzaj y mopán por el otro) y el tzeltalano clásico, cuyos rasgos pueden identificarse con las variedades contemporáneas del tzotzil-tzeltal ${ }^{6}$. Además se dispone de los códices de Dresde ${ }^{7}$, Madrid y París, que contienen información esencial a todos los niveles y cuya caracterización lingüística está todavía por determinar, aunque parece seguro que cada uno refleja una variedad maya distinta que oscila entre lenguas cholanas y las lenguas yucatecas ${ }^{8}$. La combinación de estos dos hechos, sin parangón en el resto del continente americano, posibilita trazar una historia ciertamente dilatada de las lenguas mayas y por lo tanto, se ofrece la posibilidad de poner en práctica el ejercicio de la lingüística histórica en las mejores condiciones ${ }^{9}$. Siendo ésta la situación, es inexcusable que el mayista no posea unas nociones siquiera elementales de lingüística histórica.

\section{¿Mayista filólogo o filólogo mayista?}

Una pregunta de muy complicada respuesta dentro de la mayástica actual incumbe a la propia definición del profesional que se dedica a la misma: ¿mayista filólogo o filólogo mayista? Para el observador externo hay un hecho que llama poderosamente la atención y que se torna extraordinario cuando se compara con lo sucedido en otros campos de investigación. El desciframiento progresivo que se ha venido realizando de la escritura jeroglífica maya ha sido posible gracias a la labor en primer lugar no de lingüistas, ni siquiera de filólogos, sino de arqueólogos, antropólogos e incluso etnólogos, basta como ejemplo el propio Sir John Eric Sidney Thompson (1898-1975). La situación ha sido tal - y en cierto modo sigue siendo, aunque por fortuna cada vez menos -, que dos lingüistas especializados en la diacronía de las lenguas mayas, como Campbell y Kaufman (1985, p. 193), han llegado a opinar que " [u]ntil recently, few Mayan linguists had dedicated much serious attention to Mayan hieroglyphic writing ». Lo que resulta paradójico y sorprendente es que no lo hubieran hecho antes. Algo así resultaría impensable en el campo de la egiptología o la filología de Oriente Próximo, donde los « descifradores » capitales de la escritura jeroglífica de los antiguos egipcios o del silabario cuneiforme, han sido figuras portentosas de la lingüística y/o de la filología, siempre con aportaciones impresionantes e indispensables al margen del propio desciframiento de una escritura milenaria que permanecía en el más 
absoluto de los misterios. El francés Jean-François Champollion (1790-1832), o los ingleses Sir Henry Creswicke Rawlinson (1810-1895), John Chadwick (19201998) o Michael Ventris (1922-1956) ${ }^{10}$, de cuyos conocimientos en el ámbito de la logos no es necesario hablar, confirman la necesidad de especialistas en el campo de la filólogia y la lingüística, a partes iguales, en una labor tan compleja, tediosa y en ocasiones, como en la que ahora ocupa, colosal, como es el desciframiento de una escritura.

Queda claro, pues, que este tipo de formación por parte del interesado en materias como el desciframiento de escrituras ha de ser cuanto menos sólida y fundamentada. En el plano meramente lingüístico, esa falta profunda de conocimientos ha provocado que algunos autores consideren relevantes datos que en realidad son erróneos o que simplemente no son tan importantes como parecían a primera vista. Un caso ciertamente célebre, y que no debe repetirse, es el de la " hipótesis maya-altaica ». Enunciada y defendida en solitario por el indólogo sueco Stig Wilkander (1908-1983), esta hipótesis pretendía establecer un lazo genético entre los mayas y los pueblos nativos de la órbita centro-asiática, como los mongoles, túrcicos (turcos, turcomanos, kozajos, uzbekos, etc.), tungusos y coreanos, que conformaban una polémica familia denominada "altaica " (Wikander 1967; 1970; 1970-1971). La motivación de semejante propuesta era clara: dado que la población nativa americana es en origen el resultado de diversas oleadas asiáticas que cruzaron el estrecho de Bering en época preholocénica, algunas de estas poblaciones centro-asiáticas viajaron a través del estrecho y se instalaron en América Central. Wikander, cuya especialidad eran las religiones (tenía por compañeros de discusión a Mircea Eliade o al ya citado Georges Dumézil), encontró igualmente similitudes entre los patrones religiosos de los pueblos asiáticos y los mayas. Por lo tanto, el siguiente paso era establecer la unión lingüística y así conseguir el puente cultural definitivo.

Sin embargo, las observaciones realizadas por el autor a la hora de comparar las lenguas involucradas, así como la metodología empleada, hicieron ganarse a la « hipótesis maya-altaica » con todo merecimiento el calificativo de « linguistic seven-day wonder » (Georg et al. 1998, p. 68). Varios años después, otros autores decidieron plantear ideas parecidas " sión inmediata que se extrae tras leer y analizar trabajos como estos es que en ocasiones (no siempre), el desconocimiento en un área provoca situaciones algo comprometidas que se habrían solventado con nociones elementales, en este caso, de lingüística histórica. De lo contrario, cualquier no lingüista (es decir; cualquier arqueólogo, epigrafista, antropólogo, etnógrafo, geólogo...) puede consultar un diccionario de antiguo galés, encontrar similitudes con el maya y establecer inevitablemente un vínculo genético entre las lenguas celtas y las mayas, algo que no se ha hecho todavía, pero cuya aparición no sorprendería en absoluto, visto lo visto en otras áreas ${ }^{12}$. La comparación lingüistica externa es un ejemplo que ilustra, si bien de forma un tanto exagerada, los riesgos que implica la práctica de 
una ciencia que no se ha adquirido de la manera más correcta, no porque el interesado haya accedido en ello, sino porque en ocasiones el tiempo y el esfuerzo no dan para reciclajes perfectos y efectivos al cien por cien. En el caso de la lingüística histórica, debe tenerse siempre en mente que su aplicación, al igual que ocurre con las excavaciones o el análisis sociológico de un grupo étnico, exige cierta formación que si no se adquiere en las primeras etapas de aprendizaje, luego cuesta mucho trabajo asimilar. Así, procedimientos metodológicos tan elementales para un historiador de la lengua como el reconocimiento de correspondencias fonéticas por un lado hereditarias y por otro debidas a préstamos, p. ej. las correspondencias por herencia indoeuropea en albanés, frente a las que claramente se establecen a partir de la inmensa cantidad de préstamos procedentes del latín documentados en esa misma lengua y que difieren sustancialmente de las anteriores; la distinción entre un rasgo morfosintáctico universal, es decir; que se da en casi todas las lenguas del mundo y que por lo tanto no tiene validez a efectos comparativos-genéticos, de otros muy particulares, p. ej. la interpretación irregular, pero homogénea, que hacen las diferentes lenguas indoeuropeas de la tercera persona del plural en la conjugación del verbo « ser, estar » en presente; o problemas de reconstrucción interna, p. ej. la ley de Grassmann, según la cual una secuencia de dos oclusivas aspiradas, en griego o sánscrito, se soluciona con la pérdida de la aspiración por parte de la primera: ${ }^{*} C^{h} V C^{h}>C V C^{h}$, suponen en ocasiones un obstáculo para aquellos que llegan de disciplinas « exógenas ».

De todo esto se deduce que la respuesta a la pregunta ¿mayista filólogo o filólogo mayista? debe ser la siguiente: ninguna de las dos. Al mayista, como al egiptólogo, sinólogo, sumerólogo, acadista o semitista, se le presupone una formación no sólo arqueológica y antropológica, sino lingüística y filológica, más prolongadas e intensas si cabe que las anteriores. Esa misma tradición, existente a lo largo de Europa durante los siglos XVI y XVIII, especialmente en España, Francia y Alemania, pero por desgracia para todos ahora casi desaparecida - de nuevo no por elección propia, sino porque la cantidad de conocimientos a dominar son en la actualidad cuantitativa y cualitativamente superiores a los de aquella época -, implica que en la actualidad a un lingüista interesado en las lenguas mayas, o incluso especializado en ellas, se le tilda de practicar el « intrusismo profesional ", cuando la mayística, como otras muchas disciplinas, sustenta varios de sus pilares en la labor que precisamente dichos intrusos han venido ejerciendo en los últimos años. Y es que, le pese a quien le pese, las puertas de una cultura no se abren hasta que se introduce la llave de la lengua.

\section{LAS Lenguas MAYAS}

Entrados en materia, las lenguas mayas se extienden a lo largo de Guatemala ${ }^{13}$, Belice y el sur de México. Hay un total de cinco millones y medio de hablantes, aunque no todas las lenguas cuentan con un número equitativo de 
ellos. Mientras que el k'iche', yucateco y cakchiquel son hablados por algo más de un millón de personas cada uno, al menos cinco son utilizadas por menos de cinco mil y se encuentran en serio peligro de desaparecer: teco, uspanteco, lacandón, motozintleco y sobre todo itzaj. Por el momento, han desaparecido con seguridad dos: chicomucelteco y cholti ${ }^{14}$.

La clasificación interna exacta sigue siendo motivo de debate y el siguiente cuadro (véase también Figura 1) no hace otra cosa que recoger la versión más aceptada ${ }^{15}$.

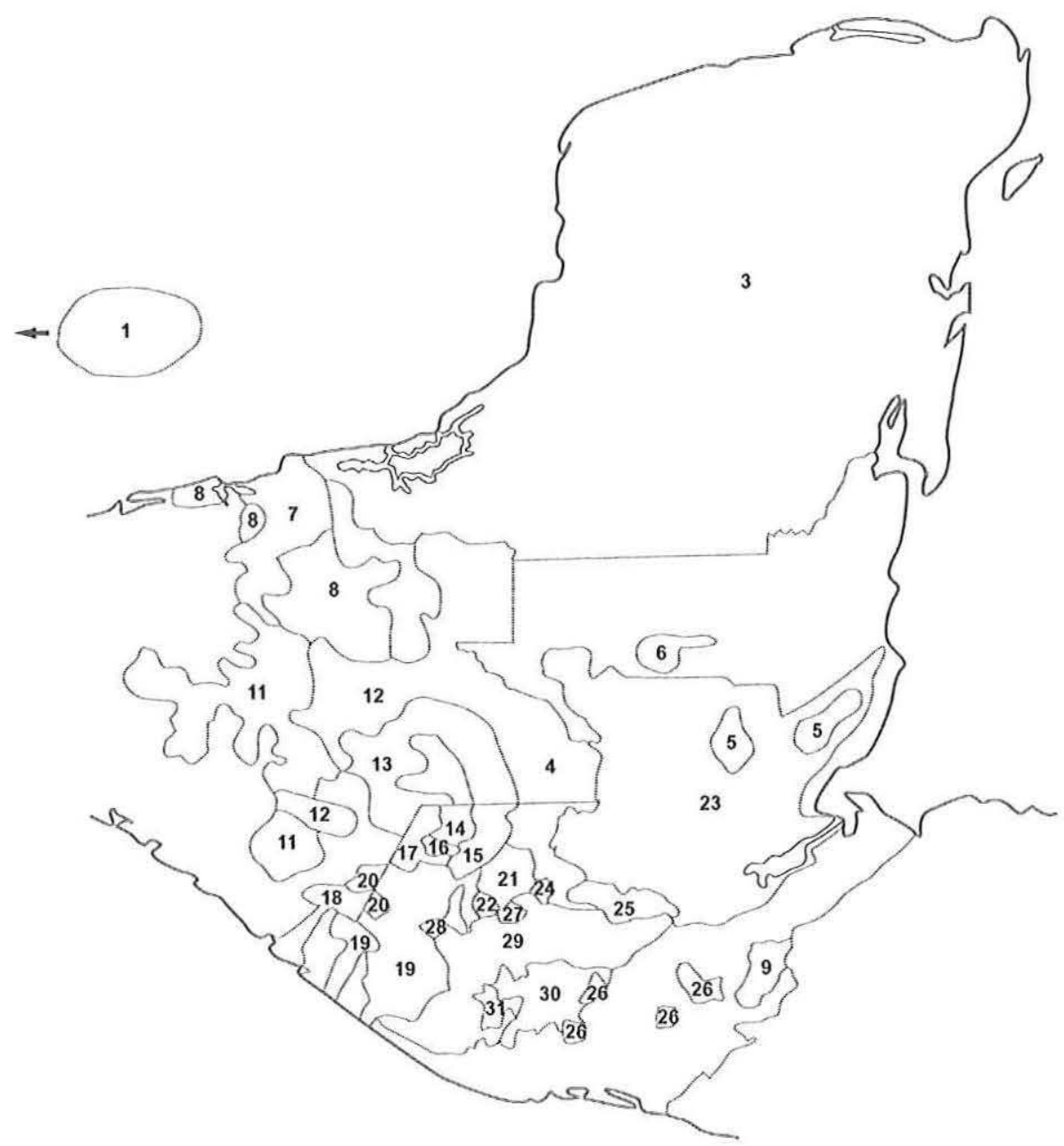

FIG. 1 - Mapa lingüístico del área maya, según Wichmann y Brown (2003) y redibujado por Georges Clément. 
Huasteco ${ }^{16}$

1. huasteco (teenek) [1]

2. + chicomucelteco (kabil) [2]

Yucateco-Maya central

Yucateco

Yucateco-Lacandón

3. yucateco [3]

4. lacandón [4]

Mopán-Itzá

5. mopán [5]

6. itzá (itza' o itzaj) [6]

Maya central

Ch'olan-Tzeltal $=$ Gran Tzeltal $=$ Gran Tzotzil

Ch'olan

Ch'ol-Chontal

7. ch'ol [8]

8. chontal (yokot'an) [7]

Chorti-Choltí

9. ch'orti' (chortí) [9]

10. $t$ choltí [10]

Tzeltal-tzotzil

11. tzeltal (b'atz'il k'op) [12]

12. tzotzil (b'atz'i k'op) [11]

Q'anjob'al-Chuj = Gran Q'anjob'al

Q'anjob'al

Q'anjob'al-Akateko-Jakalteko

13. q'anjob'al (kanjobal) [15]

14. akateko (acateco) [16]

15. jakalteko (jacalteco) [17]

Cotoque

16. motozintleco [18]

17. tuzanteco ${ }^{17}[18]$

Chuj

K'iche'-Mam

18. chuj [14]

19. tojolabal ${ }^{18}$ [13]

K'iche' (Quiche)

20. q'eqchi' (kekchí) [23]

21. uspanteco (uspantec) [24]

Poqom-K'iche'

Poqom

22. poqomchi' (pokomchí) [25]

23. poqomam (pokomam) [26]

K'iche

24. k'iche' (quiché) [29]

Caqchiquel-Tz'utujil

25. kaqchikel (cakchiquel) [30]

26. tz'utujil (tzutujil) [31] 


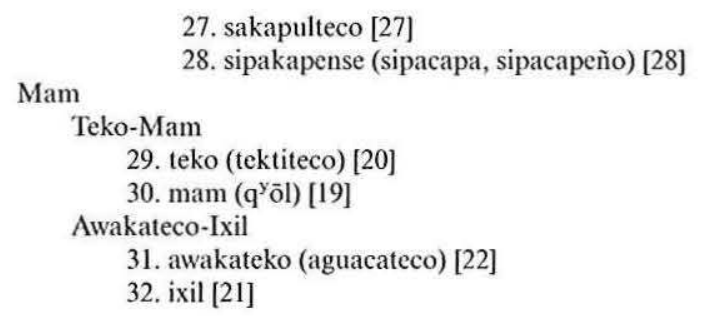

Una gran parte de los términos que aparecen en el cuadro son de procedencia náhuatl, como bien indica el sufijo derivativo -/tēka/ « ser habitante de », p. ej. huasteco <wäš- "guaje (Cresentia cujete)» + -/tēka/, chicomucelteco </čikōm(e)-/ " siete » + ōcēlö- /ōsēlō-/ « ocelote » + /-tēka/, chontal </čontal-/ " extranjero ", acateco </äka-l " junco, caña » + /-tēka/, jacalteco </ša?al/ « cabaña » + /-tēka/, motocintlec </mōto?-l « ardilla » + -tzin diminutivo + /-t'a?/ « lugar donde es abundante » + /-tēka/, uspanteco </očpān-/ « retama » + l-tēka/, sacapulteco <saka « hierba » + -pōl aumentativo + /-tēka/ o sipakapense $<$ sipak « aligator, animal sobrenatural » + äpan « río ». El resto derivan de la lengua a la que denominan, p. ej. ch(')ol </č'ol/ « indio » ${ }^{19}$, tojolabal <toh-ol " recto, firme, correcto » + $a b^{\prime} a l$ « lengua », q'eqchi' <q'eq « negro » + /či?/ " boca, lengua », k'iche' </k'î(h)-/ « muchos » + /če?/ « árbol », mam es mäm " abuelo, nieto », caqchikēl <antiguo caqchikēl kaq " rojo » +/či?/ «boca, lengua », chuj </čūx/ « baño de vapor', tzotzil <sotz' " murcielago » + -il sufijo nominal ${ }^{20}$.

A partir de evidencias no menos peregrinas se han pretendido emparentar a las lenguas mayas con el araucano, yunga, chipaya-uru, el penutio, hokan, lenca, tarascan, huave, mixe-zoque [MZ] o totonaca. Ninguno de estos intentos es aceptado por los lingüistas, lo cual, sin embargo, no ha evitado que alguna filtración errónea llegase a importantes trabajos sobre mayística. Sin ir más lejos, Ruz Lhuillier (1989, p. 13) escribía que « [t]odas estas lenguas [mayas], según Swadesh, formaban junto con el lenca y el xinca, de Honduras, El Salvador y el sur de Guatemala, el mixe de Oaxaca y el totonaca de Veracruz, un mismo grupo que denominó "macromaya", el cual mostraba conexiones con otro grupo lingüístico, el "macroazteca" en que se encontraban las lenguas de la familia del náhuatl. A su vez, todas ellas quedaban comprendidas en el complejo tejido que constituyen las lenguas americanas, derivadas lejanamente de las lenguas asiáticas que hablaban los pobladores originales de continente americano ». Nada de lo comentado en este párrafo puede tomarse siquiera en serio, ya que el trabajo de Morris (Mauricio) Swadesh o Joseph H. Greenberg (1915-2001) en cuanto a clasificación de lenguas amerindias se refiere fue en su momento rechazado de plano ${ }^{21}$. 


\section{LA ZONA LINGÜÍSTICA MESOAMERICANA}

Un área lingüística, en alemán Sprachbund, viene definida por unas determinadas características presentes en las lenguas que se vinculan a una región concreta (Campbell 1997a, p. 183) ${ }^{22}$. Así, el área mesoamericana es con diferencia el área lingüística más importante y consolidada de América. Las lenguas que se distribuyen a lo largo de este territorio no son exclusivamente mayas, sino que pertenecen a diversos troncos lingüísticos: uto-azteca (náhuatl), MZ, xinca, otomangue (excepto chichimeco-jonaz y algunas variedades pame), totonaca, tarasca, cuitlateca, tequistlateco y huave (Campbell 1997b, p. 344). En este caso concreto, todas comparten las siguientes características ${ }^{23}$ :

1. Posesión nominal, p. ej. pipil i-pēlu ne täkat «su-perro el hombre », es decir, « el perro del hombre ";

2. Locativos formados a partir de raíces nominales y pronombres posesivos tz'utujil $\check{c}-w-\bar{x} x$ « detrás de mí », donde $c$ - « en, a », $w$ - « mío, mi », $\bar{l} x$ « espalda »;

3. Sistemas numerales vigesimales;

4. Orden sintáctico VOS, VSO, SVO, es decir, el verbo nunca debe aparecer en posición final. Como consecuencia de ello, no existen construcciones concordantes entre verbo y sujeto - objeto;

5. Infinidad de calcos semánticos (expresiones prestadas palabra por palabra, como por ejemplo inglés blue-blood $\rightarrow$ español sangre azul, o alemán Sturmgewehr $\rightarrow$ inglés assault rifle), p. ej. rodilla = cabeza de la pierna, boa = ciervo-serpiente, huevo $=$ piedra o hueso del pájaro, etc.

Wichmann (2006b) ha reanalizado estas características areales a la luz de nuevos trabajos en materia de tipología lingüística, en concreto del trabajo de Haspelmath et al. (2005), un atlas en el que se recogen, organizadas de forma estadísticas y a través del uso extensivo de mapas, centenares de lenguas que se presentan según la naturaleza tipológica de las mismas. Así, los rasgos primero, tercero y cuarto - el segundo y quinto no aparecen glosados en el atlas - resultan ser en efecto muy característicos del área mesoamericana a excepción del último, bien porque está formulado en términos de negación, bien porque en otras muchas áreas del mundo se prefiere un orden sintáctico concreto y no varias opciones, como en el caso que ocupa. Para este problema Wichmann of rece como solución reconsiderar la formulación original y ceñirla únicamente al orden sintáctico de los componentes $\mathrm{O}$ y $\mathrm{V}$, es decir OV, detalle éste que sí caracteríza al área mesoamericana. Por otro lado, Wichmann (2006b) propone otros cuatro rasgos propios de aquella área, cuya validez parece tan legítima como la de las propuestas por Campbell et al. (1986):

6. Pronombres indefinidos idénticos a la palabra para « uno »;

7. A la existencia de sustantivos posicionales (aquellos que se utilizan para expresar relaciones espaciales), debe sumarse la de algunas preposicones comunes de uso general; 
8. Los pronombres interrogativos se colocan al inicio de la frase, como p. ej. en español ¿qué haces hoy? o ¿dónde está mamá?;

9. Ausencia de construcciones de doble negación, como p. ej. en castellano yo no vi nada, prefiriéndose estructuras con una única negación, como p. cj. en alemán ich habe nichts geheben " no he visto nada ».

Es importante conocer estos datos, puesto que de este modo se evitan conclusiones erróneas acerca de posibles relaciones genéticas o de préstamos en direcciones erróneas. Recientes estudios han confirmado que el ámbito lingüístico de esta región coincide plenamente con el cultural (Campbell et al. 1986; Kirchhoff 1943), algo no muy frecuente. Los aspectos tanto lingüísticos como culturales - al menos los conocidos a través de evidencias materiales - debieron formarse durante el período mesoamericano preclásico (ca. 1.500 a.C. al 100 d.C.), con posibles influencias olmecas. La existencia de estas áreas permite identificar con suma facilidad elementos externos, lo cual es de vital importancia a la hora de corroborar por ejemplo migraciones o invasiones, es decir, cuestiones que se alejan de lo meramente lingüístico, pero a las cuales puede llegarse de forma indirecta a través de esta disciplina.

\section{LiNGÜÍSTICA HISTÓRICA Y (PRE)HISTORIA MAYA}

Se denomina "protomaya » [PM] a la lengua de la cual derivan todas las actuales hablas mayas. Dado que no se dispone de testimonios escritos en lengua PM, es necesaria la reconstrucción de la misma mediante diversas técnicas que las lingüísticas histórica y comparativa han desarrollado durante los últimos dos siglos. Hasta que el desciframiento de la escritura jeroglífica no ha entrado en una etapa de consolidación, los lingüistas pensaban que la reconstrucción del PM era relativamente sencilla, ya que la evolución fonética y morfológica de estas lenguas no presentaba ninguna característica digna de ser calificada como anómala o irregular ${ }^{24}$. Sin embargo, con ayuda de los testimonios encontrados, analizados, comprendidos y traducidos, el estado actual de la cuestión dará un paso al frente, puesto que por regla general estos hallazgos no hacen más que confirmar o desestimar la labor hecha hasta el momento. Es decir, la escritura jeroglífica desempeñará el rol de juez, del mismo modo que lo hizo el hitita con las lenguas protoindoeuropeas $^{25}$.

En el siguiente cuadro se recogen seis ejemplos muy elementales para ilustrar cómo funciona una vertiente del método comparativo (Campbell 1999, p. 125):

\begin{tabular}{|c|c|c|c|c|}
\hline K'iche' & Tzeltal & Yucateco & Huasteco & Proto-maya \\
\hline$y a \bar{h}$ & ya & yah & yah- & */rāh-I "caliente, picante » \\
\hline ri? & yix & yilih & yeh- & */ri?ix/ " (hombre) viejo, anciano " \\
\hline$r-$ & $y-$ & $y-$ & $y-$ & "suyo, suya " \\
\hline
\end{tabular}




\begin{tabular}{|c|c|c|c|c|c|}
\hline yaš & yaš & ya?aš & yaš- & */ra7šl & " verde" \\
\hline war & way & way & way & */war/ & "dormir » \\
\hline$y \cdot \vec{a} x$ & yah & $y a h$ & $y a ?$ & */yāh/ & «enfermo " \\
\hline$k^{\prime} a y$ - & $k^{\prime} a y-$ & $k^{\prime} a y^{\prime}$ & $\check{c}^{\prime} a y-$ & */k'ay-I & « vender $\|^{26}$ \\
\hline
\end{tabular}

La reconstrucción de una (proto)lengua se inicia con la identificación de material léxico, cuya presencia en el vocabulario de una lengua dada no se explica mediante préstamo o cualquier otro tipo de mecanismo de contacto lingüístico no genético, como la contaminación o los calcos semánticos antes mencionados. Tras esta fase, no exenta en ocasiones de problemas, se procede al establecimiento de correspondencias fonéticas, para lo cual es necesario observar patrones sistemáticos en el corpus léxico analizado. La tabla ofrecida recoge palabras caracterizadas por los fonemas $/ \mathrm{r} / \mathrm{e} / \mathrm{y} /$, que dependiendo de la posición que ocupan dentro de la palabra - inicial, media o interna, final - se comportan de un modo $\mathrm{u}$ otro. Al mismo tiempo, resulta indispensable prestar atención a los aspectos semánticos (si el significado de los términos comparados no es idéntico o similar, hay que elaborar una explicación convincente sobre la motivaciones que han conducido a la aparición de diferentes significados) y morfólogicos (distinguir perfectamente entre raíz y formantes de cualquier tipo).

¿Cómo puede contribuir la lingüística histórica a nuestro conocimiento de la (pre)historia maya a partir de tablas como éstas? Kaufman (1976) propone que el Uiheimat del PM, es decir, la patria originaria, está localizada en torno a los montes Cuchumatanes (Guatemala), cerca de Soloma, en Huehuetenango, y calcula que los primeros hablantes de la lengua PM se remontan al menos hasta ca. 2200 a.C. Estas conclusiones se alcanzan tras analizar el vocabulario PM (extraído de esas tablas), que refleja una alta especialización agrícola, con el maíz como figura central. Resulta evidente que los usuarios de la lengua PM aprovecharon los recursos naturales de las tierras altas y bajas de aquella región. Siguiendo las diferentes migraciones poblacionales y las evoluciones léxicas, Kaufman establece hasta siete estadios evolutivos, cada uno de ellos caracterizado a nivel lingüístico, (pre)histórico, arqueológico y étnico. Así, entre 1500 y 1000 a.C. es posible establecer que los huastecos ya se habían separado del tronco común ${ }^{27}$, mientras que en el curso inferior del río Usumacinta, en el Petén, se instalaron los grupos yucateco y ch'olano-tzeltal. Más tarde, ca. 200 d.C., los cholanos llegan a las tierras altas de Chiapas, antes ocupadas por hablantes de lenguas MZ. Después llegarían los yucatecos que, aunque de forma secundaria, vendrían a colaborar en la consolidación de la cultura clásica maya (250900 d.C.). Por su parte, la rama k'iche' ocupó el sureste de Guatemala en el 1200 d.C., lugar al que los nahuatlatos no pudieron llegar antes del 800 d.C. (Campbell 1978; 1997a, pp. 185-187). La rama poqom expulsa a xincas del este de Guatemala, por debajo del río Motagua y tras la conquista del valle de Rabinal por los k'iche', surge en ca. 1250 la división formal entre poqomam y poqomchí. De este modo la lingüística histórica, apoyada por datos arqueológicos, pone de 
manifiesto que las culturas preclásicas fueron fundadas por diferentes grupos étnicos no-mayas: Izapa es lingüísticamente $\mathrm{MZ}$, al igual que Chalchuapa, Kaminaljuyú y Abaj Takalik, ya que la opción maya es cuanto menos dudosa ${ }^{28}$.

\section{Breve descripción del PM}

El caso de la reconstrucción PM es bastante particular. Mientras que otras protolenguas deben conformarse con reflejar el esqueleto de diversos estratos o niveles de evolución, incluso una vez se ha alcanzado el tope que las lenguas documentadas permiten, el PM da cuenta de una lengua muy uniforme, pudiéndose afirmar que lo que se reconstruye es lo que, muy probablemente, fue hablado hace cuatro mil años. La labor de Kaufman y Campbell, citados en más de una ocasión a lo largo de este estudio, ha sido crucial para establecer las bases de la reconstrucción protomaya. El siguiente cuadro recoge el inventario fonético PM de acuerdo con estos autores ${ }^{29}$ :

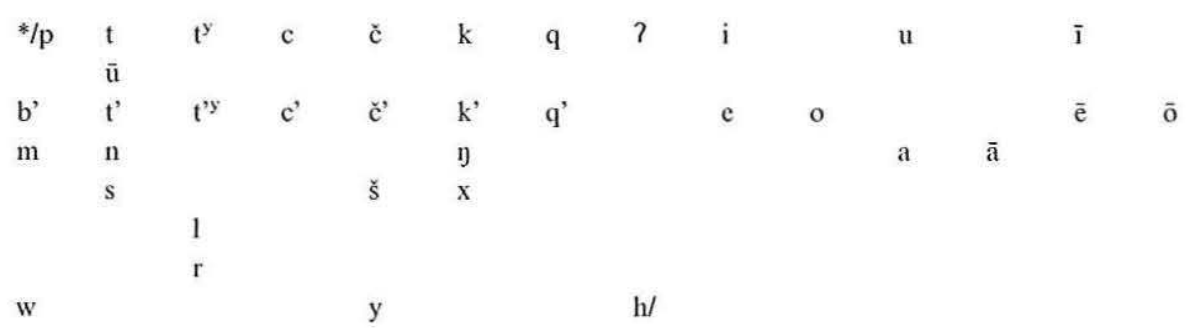

Este inventario estaba sujeto a una serie de restricciones fonotácticas, que se observan en las restricciones compositivas de las estructuras silábicas y radicales. Kaufman (1976) presentaba las siguientes estructuras: ${ }^{*} \mathrm{CV}(:) \mathrm{C}$, ${ }^{*} \mathrm{CVhC}$, ${ }^{*} C V S C,{ }^{*} C V(:) ? C \mathrm{y} * C V ? V C{ }^{30}$. No en vano, Wichmann y Brown (2004), tras comprobar que las correspondencias fonéticas establecidas por Kaufman no respondían por completo a todo el material etimológico que se utilizaba, han presentado pruebas definitivas que hablan a favor de la existencia no de cinco estructuras silábicas, sino de diez. A pesar de este gigantesco paso, ciertas deficiencias metodológicas impiden por el momento poder lanzar un grito de éxito definitivo. Por ejemplo, la clave de una reconstrucción lingüística está en la identificación fehaciente y sólida de estructuras radicales, muy al contrario de lo que piensan Wichmann y Brown ${ }^{31}$. De hecho, las correspondencias fonéticas pueden darse entre préstamos, mientras que las estructuras radicales no. Por otro lado, uno de los inconvenientes más graves que presenta la propuesta de Wichmann y Brown es el postulado de un tercer rasgo cuantitativo en las vocales (oposición breve : larga : ultra-larga, con obvias consecuencias en el establecimiento de nuevas estructuras radicales) que, al margen de su frecuencia tipológica 
a la que los autores hacen bien en no valorar, no se ha conservado en ninguna lengua documentada. Esto, que en esencia es un postulado ad hoc, se antoja inviable desde un punto de vista metodológico porque sería aceptar el hecho de jugar con ases en la manga, es decir, puesto que las lenguas documentadas no han conservado el rasgo propuesto por los autores, ese rasgo puede ser cualquiera ${ }^{32}$.

Al margen de estos problemas actuales, muchos han sido los cambios que ha experimentado el inventario fonético PM y ha sido el uso conjunto de filología y lingüística histórica el que ha conseguido ofrecer un cuadro final coherente y detallado. Un ejemplo es el célebre caso de la discutida existencia de los fonemas */kw/ y */k'w/. Según McQuown (1955) estos dos fonemas podían postularse a partir del huasteco. Sin embargo, en el vocabulario huasteco antiguo [HA] de Carlos de Tapia Centeno, escrito en 1727, aparecen registradas formas sin las susodichas labiovelares, que sin embargo sí se conservaban en las diferentes hablas modernas (Campbell 1990a, pp. 89-90) ${ }^{33}$. Este hallazgo confirmaba que $* / \mathrm{k}^{\mathrm{w}} / \mathrm{y} * / \mathrm{k}^{\prime \mathrm{w}} /$ son fonemas secundarios, sujetos a la evolución HA $k($ ') $+o / u+$ $w / y / h / 2+V>$ dialectos contemporáneos $k\left({ }^{\prime}\right)^{w} V w / y / h / 7$, p. ej. HA <coyen $>$ " masa » $>k$ "en " agrupado, apilado » (dialecto de Veracruz), HA <tzanaco $>$ " judía »> tsanak" (Potosí), čanak" (Veracruz), HA <cohuych> " mazorca fresca " $>k$ "ï̌ (Potosí), $k$ "ïts (Veracruz).

En el ámbito morfosintáctico, la reconstrucción PM se ha respaldado en una constitución estructural muy similar entre las distintas lenguas mayas, lo cual ha facilitado, dentro de lo que cabe, la labor del comparativista. Como en todas las familias lingüísticas, es el verbo la categoría que más atención ha recibido, por acumular una mayor complejidad morfológica. Ya incluso en época PM puede constatarse que la principal oposición que se establece en el sistema verbal de estas lenguas no es entre tiempos, sino entre aspectos, así como entre la condición transitiva o intransitiva de la raíz ${ }^{34}$. Un punto muy importante de la naturaleza morfosintáctica del PM es su naturaleza ergativa. Dicho rasgo tipológico, que se observa en otras lenguas tan dispares como el vasco, georgiano o sumerio, no ha continuado en algunas lenguas como el yucateco o el ch'olano clásico. Por el contrario, aquellas lenguas han desarrollado un sistema acusativo (" split ergativity ») para los enunciados con verbo imperfectivo, dejando el sistema ergativo para los enunciados con verbo perfectivo. Para hacer esto se han introducido modificaciones secundarias, alterando determinadas categorías morfológicas (p. ej. en mocho la categoría de persona ha cambiado con respecto al modelo PM) o sintácticas (p. ej. la subordinación en jacalteco o tzotzil). El resultado es que p. ej. en yucateco la partícula $k$ caracteriza a verbos tanto transitivos como intransitivos de aspecto imperfectivo (acción no concluida), mientras que $t$ y $h$ corresponden a verbos de aspecto perfectivo (acción concluida) transitivos e intransitivos respectivamente ${ }^{35}$. De manera más profunda se vieron afectados los índices personales, que presentan una organización concreta de acuerdo con el sistema dominante ergativo o acusativo de la lengua, aunque sin llegar a crear 
juegos de sufijos independientes para cada uno. Otro punto relevante, y de profundo interés desde una perspectiva comparativa en tanto en cuanto determina la configuración del sistema verbal protomaya, es la denominada voz antipasiva ${ }^{36}$, que en esencia aparece cuando se omite el objeto de un verbo transitivo, debiéndose transformar éste en un verbo de valencia intransitiva, p. ej. yucateco $t$ a šok-ah « lo estudiaste » frente a šòok-n-ah-eč « estudiaste », donde el tipo de raíz, el alargamiento de la vocal radical con tono descendente y $-n$ - son sus señas de identidad.

El orden sintáctico PM debió ser VOS ${ }^{37}$, conservado en yucateco, tzotzil y tojolabal, con la posibilidad de VSO ${ }^{38}$, documentado en mam, q'anjob'al, jacalteco y en un dialecto chuj. El ch'orti' es el único que refleja SVO (con VS como cabría esperar en las oraciones intransitivas que siguen un patrón ergativo), mientras que huasteco, tzeltal, chuj, acateco, motozintleco y k'iche' utilizan VOS y VSO, aunque con clara superioridad del primero.

\section{LAS INSCRIPCIONES DEL MAYA CLÁSICO}

Para la reconstrucción del PM es incalculable el valor del material que suministran las inscripciones jeroglíficas de los reinos mayas. El primer paso era lógicamente leer dichos jeroglíicos, cuestión ésta que avanza lenta pero de forma muy convincente ${ }^{39}$, y después entender las lenguas que se escondían tras ellos (Houston et al. 2000) ${ }^{40}$. Sea como fuere, la escritura maya también ha contribuido a la causa lingüística, y de forma indirecta, a la mejor comprensión de la prehistoria maya. Por ejemplo, el hecho de poder datar la evolución fonética PM */k/ > ch'olano clásico /čl antes de que se comenzará a usar la escritura clásica maya, implica la posibilidad de caracterizar a una serie de lenguas con esa evolución y, por ende, el espacio físico que ocupaban antes y después de que tuviera lugar ese cambio. Un ejemplo muy ilustrativo con respecto a la evolución fonética aludida puede observarse en Chac $\mathrm{Mol}$, el dios de la lluvia y las tormentas, cuyo nombre en escritura monumental resulta ser la combinación de los signos $<$ ča $>$ y $<\mathrm{ki}>$ (donde la última /i/ es en este caso, y hasta que se demuestre lo contrario, una vocal muda a la que se recurre cuando es necesario plasmar estructuras silábicas (VV), que representan ch'olano clásico /čahk/ <PM */kahoq/ « trueno », cfr. itzaj /čāk/, mopán /čałak/, tzotzil /čauk/, tzeltal /čahwuk/, poqomchi' /kohoq/, q’eqchi' /kāq/ o aguacateco /k'oq/.

\section{Conclusión}

Con lo aquí expuesto se espera haber demostrado que la lingüística histórica no debe ser ignorada o infravalorada. El estudio comparativo de cualquier tipo de 
lenguas es un proceso clave del que pueden extraerse todo tipo de conclusiones útiles no sólo para la propia lingüística, sino para otra variedad inmensa de especialidades científicas que desde luego no pueden permitirse el lujo de prescindir de los datos aportados por éste. Además, resulta a todas luces obvio que en una disciplina de estas características el avance sólo puede llegar de la mano de trabajos pluridisciplinares, donde la suma de conclusiones obtenidas desde distintos puntos de vista confirmarán, o rechazarán, la verosimilitud de cualquier propuesta. Por lo tanto, cuanto más completa sea la formación del investigador, mejores serán los resultados a obtener y esto pasa sin duda alguna por el desarrollo de un programa de estudios lingüísticos centrado en el aprendizaje y análisis de lenguas nativas americanas, que de ningún modo se conocen fragmentaria o parcialmente, tal y como afirma el tópico. *

* Manuscrit reçu en janvier 2006, accepté pour publication en décembre 2006.

\section{NOTAS}

Me gustaria expresar mi más sincero agradecimiento a los doctores Valentina Vapnarsky, Jean-Michel Hoppan, Alfonso Lacadena, Soren Wichmann y Miguel Figueroa-Saavedra, que han revisado y corregido pacientemente las versiones preliminares de este escrito. Asimismo, las indicaciones aportadas por dos lectores anónimos de la revista han resultado ser de un inmenso valor. Huelga decir que cualquier error queda bajo mi entera y absoluta responsabilidad.

1. Evitense las formas incorrectas ${ }^{* *}$ mayecense, ${ }^{* *}$ mayance $0 *$ mayense, al ser maya sustantivo y adjetivo al mismo tiempo.

2. La situación empeora si se tiene en cuenta la actitud académica entre los siglos XVI y XVIII, donde el aprendizaje de cualquier lengua nativa, en especial las mesoamericanas, estaba al alcance de cualquier interesado, dada la existencia incluso de cátedras que ofrecian estos servicios. Súmese a esto el interés que los soberanos españoles, así como las entidades eclesiásticas, mostraban ante tal riqueza lingüística, la cual veían como un vehículo de expansión politica, económica y religiosa, más que como un obstáculo para llevar a cabo sus intenciones en el continente americano. Un ejemplo de toda esta preocupación es el decreto promulgado en 1570 por el rey Felipe II (1556-1598), que convertía al náhuatl en lengua oficial de las Indias. Un tratamiento magnífico sobre la consideración que las lenguas nativas americanas recibían por parte de la Corona espanola y de la Iglesia puede verse en Zimmermann (1997) y Heath (1972, pp. 49-67).

3. Campbell (1990a, p. 87) comenta al respecto que « [m]any non-specialist are surprised to find out that a number of American Indian languages have abundant written attestations earlier than those for several European languages ».

4. Una interesante e instructiva lectura a posteriori de esta obra puede ser la revisión que de ella hace Aikhenvald (2002), más la respuesta a ésta por el propio Campbell (2003).

5. Campbell et al. (1978) es un fantástico catálogo que recoge 2.513 referencias bibliográficas, publicadas y no publicadas, hasta 1976. Por su parte, Campbell y Kaufman (1985) ofrecen el mejor resumen sobre lingüistica maya que se ha publicado hasta la fecha.

6. Para un resumen de la cuestión, véase Wichmann (2006a). En cualquier caso, son de consulta obligada los trabajos que iniciaron el reconocimiento lingüístico de las inscripciones mayas, inter alia Bricker (1986), Campbell (1984), MacLeod (1984; 1986) y Schele (1982).

7. Existen serias dudas en cuanto a la autenticidad del códice Grolier, por eso no se enumera junto a los clásicos de Dresde, Madrid y Paris. Sobre el carácter reciente del códice Grolier, véase entre otros Baudez (2002). 
8. Algunos trabajos de referencia obligada siguen defendiendo la posición yucateca, según la cual todo códice maya está compuesto en lengua yucateca clásica (p. ej. Campbell y Kaufman 1985, p. 194; Campbell 1997b, p. 165; 1990a, p. 18), lo cual queda lejos de ser cierto una vez se analiza en profundidad el material original (Lacadena 1997). En cuanto a la supuesta falsedad del más recientemente descubierto de los códices, el llamado Grolier, especialistas como Michael D. Coe o Christophe Helmke (comunicación personal) reiteran que se trata de un documento verdadero y genuino, y que las posiciones en contra están mal fundadas o no se ajustan a la metodología que exige un juicio como ése.

9. A modo de curiosidad, la primera gramática de una lengua europea que no sea ni el griego ni el latín es la española (1492), a la que siguen las del letón (1531), finés (1543), alemán (1573) o inglés (1586). La primera gramática de una lengua maya es la del cakchiquel(1550), seguida del k'iche' (1550), q'ekchi (1554) o huasteco (1560) (Campbell 1990b, p. 124).

10. Aunque Ventris fuera licenciado en arquitectura, nunca llegó a ejercer como tal, y sus preocupaciones jamás giraron en torno a esta disciplina. De hecho, hubo un momento en su vida en el que todo pasaba por el análisis de textos micénicos. Pese al desciframiento de la escritura lineal $\mathrm{A}$, su vida se convirtió en un asunto monotemático para el que ni siquiera su esposa o hijos eran merecedores de tiempo alguno. Ventris fallecería en un accidente automovilistico en la noche del 5 de septiembre de 1956. Georges Dumézil (1898-1986) comentaría con todo el acierto del mundo que " devant les siècles, son auvre est faite ».

11. En especial Frankle (1984a y b), aunque sus propuestas no son mejores. En este caso la autora se aproxima a la comparación entre el tronco maya y las lenguas túrcicas mediante el análisis de elementos morfológicos. Sin embargo, ninguna de las comparaciones aportadas por Frankle cumple los requisitos mínimos que la lingüística histórica exige para su aceptación, p. ej. el uso de afijos monosilábicos, como los derivativos verbales con una sola vocal utilizados por la autora en su artículo de 1984b, no pueden considerarse válidos porque muchas lenguas del mundo presentan sufijos similares, sino idénticos.

12. Dell Hymes (ver especialmente Hymes 1965), filólogo y lingüista, autor de trabajos sobre cómo combinar y potenciar la interrelación de diferentes disciplinas, en su juventud llegó a aceptar alguna de estas hipótesis, en concreto la quechua-altaica (Bouda 1960), llegando a afirmar que « [c]learly this attempt [...] confirms the genealogical relationship of Quechua with Altaic, letting one recognize that still another ancient American Kultur-sprache stems from Asia » (Hymes 1961, p. 362).

13. Mayers (1966) ofrece una perspectiva general de la variedad lingüística guatemalteca a través del análisis de sus diversas lenguas, sobre todo mayas. Sin embargo, las descripciones son un tanto pobres y generales: no hay tratamiento fonológico y al final de cada sección se incluye una lista de palabras y expresiones del tipo " hola », " gracias ", " ¿qué tal estás? " y un texto trascrito y traducido. La consulta a McQuown (1967) y Edmonson (1984) es indispensable.

14. Ver www.ethnologue.com.

15. Ver Campbell (1997b, p. 163). El signo + significa « lengua muerta ». Para las estimaciones de hablantes véase Wichmann (2006b). En Moreno Cabrera (2003, pp. 808-813) pueden encontrarse las denominaciones de estas lenguas castellanizadas, aunque su utilidad es nula, puesto que ningún repertorio bibliográfico las refleja. Esto crea en el investigador una confusión innecesaria, p. ej. celdal por tzeltal. Por otro lado, olvida mencionar al motozintleco y tuzanteco, grave despiste teniendo en cuenta que se utiliza la misma fuente bibliográfica que en la presente nota. Además, el autor afirma que el chicomucelteco tiene menos de 1.000 hablantes (ibid., p. 812), cuando se trata de una lengua muerta desde hace al menos una década (tampoco informa de la desaparición del choltí). Moreno Cabrera ha decidido quizás seguir la información recogida en la página web de Ethonologue (véase nota anterior) en la decisión de considerar el chicomucelteco como una lengua viva (pese al calificativo « extinct » que le merece esa página y a la bibliografía especializada, que la considera lengua muerta), pero a la hora de recolectar lenguas por debajo de los diez mil hablantes se deja unas cuantas, p. ej. itzaj, siacapense o mopán (ver la parte « ¿Mayista filólogo o filólogo mayista? »).

16. Robertson y Houston (2003) presentan evidencias lingüisticas y arqueológicas que supuestamente lo vincularían a las lenguas cholanas-tzeltal, es decir, a la rama maya occidental. Sin embargo, en 
lo que respecta a las pruebas lingüisticas, éstas son escasas y de entidad no muy relevante (difusión de una isoglosa, evolución parcial del sistema pronominal e innovación en la marca verbal de aspecto imperfectivo). El albanés, lengua de reconocida autonomía dentro del tronco indoeuropeo, comparte hasta seis rasgos fonológicos y morfológicos con el grupo eslavo y cuatro con el indo-iranio, todos de mayor peso que los aducidos para la relación huasteco-tzeltalano (confusión de los timbres vocálicos indoeuropeos ${ }^{*} a{ }^{*} o$ y de las oclusivas sonoras y sonoras aspiradas, nominativo plural temático *oi frente a *-os, desinencias de voz media del tipo *-omai, *-etai sin rastro del formante *-r, etc.), y hasta el momento ningún lingüista ha propuesto movilizar al albanés e incluirlo junto a las lenguas eslavas o en el ámbito asiático (Ledesma 1996, pp. 38-39). Sea como fuere, lo que sí parece cierto es que el huasteco se encuentra mucho más cercano a la rama tzeltalana que a la yucateca, algo que, en opinión de los autores, puede corroborarse mediante los datos arqueológicos. Será necesario un estudio diacrónico en profundidad de todas las fuentes disponibles el que dicte sentencia en cuanto a la disposición taxonómica del huasteco, que cada vez está más lejos de ser una lengua aislada dentro del conjunto maya.

17. Kaufman (1976, pp. 102-103) opina que ambas lenguas son en realidad los dialectos superior (motozintleco o mocho) e inferior (tuzanteco) de una variedad denominada « cotoque »/qato?k'/, que habría desaparecido. Otros autores prefieren considerar el tuzanteco como dialecto del motozintleco. Puesto que hay fundadas razones para considerar (y aceptar) ambas posibilidades, aqui se optará por la primera, en tanto que una introducción debe of recer el cuadro completo de las lenguas mayas, siendo la relación motozintleco-tuzanteco un punto al que tarde o temprano ha de llegarse, así que cuanto antes sea, mejor.

18. La clasificación exacta del tojolabal ha sido ampliamente discutida, sobre todo por John S. Robertson (1977), que considera que esta lengua pertenece al grupo tzeltalano. Campbell y Kaufman (1985, p. 190) opinan que las semejanzas con ese grupo se deben al intenso contacto cultural y al hecho consecuente de que multitud de tojolabales son bilingües con el tzeltal.

19. Este etnónimo se identifica por etimología popular con /čol/ « milpa », donde no hay presencia de glotal. Por su parte, Campbell (1997b, p. $\left.403 n^{\circ} 29\right)$ opina que deriva de /č’ol/ "indio ", término empleado entre las lenguas cholanes, sin que especifique concretamente cuál es la lengua originaria del término. Como uno de los lectores anónimos de la revista indica, en q'eqchi la palabra ch'olwiinq significa " salvaje ", por lo tanto, podría pensarse que estos denominaron así a los grupos vecinos que consideraban salvajes, y que después generalizaron el término, exactamente igual que en el caso de la palabra náhuatl chontalli en relación con los chontales.

20. Ver Campbell (1997b, p. $\left.403 \mathrm{n}^{\circ} 25-45\right)$. Estas etimologias tienen incluso su aplicación histórica, ya que por ejemplo en jakalteko </ša?kal/ " cabaña » se observa como el español tomó esta palabra después del siglo xviII, período durante el cual tuvo lugar la evolución fonética castellana $/ \tilde{s} />/ \mathrm{x} /$, escrita $<j>$. Esto demuestra que la codificación de la lengua jacalteca por parte de los misioneros españoles fue bastante más tardia que la de otras lenguas de la región, cuyas informaciones llegaron durante el siglo XVI y donde por supuesto dicho cambio fonético todavía no había acontecido. En efecto, las primeras descripciones del jacalteco no han aparecido hasta bien entrado el siglo $\mathrm{xx}$ (McQuown 1967, p. 5).

21. La obra más célebre sobre la clasificación de las lenguas amerindias es sin duda Greenberg (1987), aunque no menos lo es la contundente y definitiva revisión de Campbell (1988b).

22. Aunque en fechas recientes se ha preferido adoptar una postura algo menos conservadora, poniendo en duda las bases teóricas del término, lo cierto es que por el momento el concepto de Sprachbund permite abordar el estudio de estas agrupaciones lingüísticas desde una perspectiva clara y objetiva, en el sentido de que, con indiferencia de las vicisitudes históricas, a veces sencillas, otras sumamente complejas, que envuelven a cada una de ellas, es posible no caer en la tentación de postular agrupaciones genéticas indebidas o/y profundizar en cuestiones de contacto lingüístico. Yasugi (1995) y Stolz (2002) ofrecen magníficos estudios sobre este polémico asunto, concentrándose ambos en el área mesoamericana. Por otro lado, resulta metodológica y pedagógicamente apropiada la lectura de Tuite (1999), donde se demuestra cómo la aplicación del término Sprachbund sobre el 
área caucásica no se sustenta en datos filológicos, siendo necesario el rechazo del mismo para esa zona.

23. Aunque suelen citarse otras muchas más, las cinco que se apuntan aquí están presentes en todas las lenguas del área mesoamericana, mientras que el resto no (Campbell 1997b, pp. 345-346).

24. Algunos cambios fonéticos, citados hasta la saciedad incluso en manuales generales de lingüistica histórica, son $\mathrm{PM} * / \mathrm{r} />y$ en huasteco, yucateco, ch'olano-tzeltal y q'anjob'al-chuj (excepto motozintleco, donde $\mathrm{PM} * / \mathrm{r} />\dot{c})$, $\mathrm{PM} * / \mathrm{y} />h$ en q'eqchi' y $x$ en k'iche'-mam, PM $* / \mathrm{a} />i$ en ch'ol-chontal, mopán e itzaj (en contextos muy determinados) y el Lautverschiebung o mutación consonántica del grupo mam según la cual $\mathrm{PM} * / \mathrm{r} />t, * / \mathrm{t} />\check{c}, * / \check{c} />\check{c} \mathrm{y} * / \check{s} />\grave{s})$.

25. Quizás sea necesario traer más a menudo a colación la historia de las « laringales », glorioso episodio de la lingüistica indoeuropea, y gracias a las cuales el método comparativo dio el espaldarazo definitivo para comprobar hasta que punto se trataba de una aplicación científica y sobre todo, efectiva. Ferdinand de Saussure (1857-1913), fundador de la lingüística moderna, postuló la existencia de dos " coeficientes sonánticos ", escritos $A$ y $Q$, tras observar diversos fenómenos fonéticos vinculados a las vocales de varias lenguas indoeuropeas. Puesto que resultaba imposible demostrar materialmente la existencia de dichos fonemas, ya que ninguna lengua los había conservado, la comunidad científica de 1879 , año en el que esta propuesta es formulada por primera vez, ignora al joven Saussure. No sería hasta 1915, dos años después del fallecimiento del excepcional lingüista suizo, cuando un arqueólogo checo, profesor en Viena, de nombre Bedřich Hrozný (1879-1952) traducía los primeros textos en hitita, lengua que para sorpresa de muchos conservaba gráficamente los fonemas postulados por Saussure, de tal modo que su *Aenti « contra, frente a, ante » (actual notación * $h_{2}$ ánt-i) > griego \&́vtí, latín ante, osco ant, sánscrito ánti, aparecía en hitita como hanti. Investigaciones posteriores confirmaron la teoria de Saussure y el semitista danés Herman Moller (1850-1923) bautizaría estos nuevos fonemas indoeuropeos con el nombre de « laringales », ya que en protosemítico dichos sonidos causan los mismos efectos que los homónimos en indoeuropeo, con la diferencia de que en éste último todavía está por concretar las características fonológicas de los mismos. Véase a modo introductorio Villar (1996, pp. 200-205) y más en profundidad Winter (1960).

26. Nótese que no todas las formas citadas significan lo mismo, como en el caso de las anteriores. La forma tzeltal significa " cantar », mientras que yucateco " cantar, aclamar, pregonar para la venta » y huasteco " comprar », apuntan a que efectivamente el significado original en protomaya era " vender ", tal y como se ha conservado en k'iche'. Las variaciones semánticas que han tenido lugar están vinculadas a circunstancias sociales: la venta en las sociedades mayas, como en otras tantísimas, se realizaba en mercados donde los interesados gritaban y "cantaban " las cualidades y ofertas de su mercancía. England (1996) ofrece decenas de ejemplos con desarrollos semánticos particulares mayas, siendo esta obra además una magnifica introducción general a estas lenguas.

27. Algunos cambios fonéticos casi comunes a todas las lenguas mayas, p. ej. PM*/r/> y o PM*/q/ $>k$, tienen también lugar en el huasteco, aunque de forma independiente. Para una opinión contraria, ver Robertson y Houston (2003, pp. 725-726).

28. Ver Campbell (1978; 1988a). Resulta especialmente esclarecedor Campbell y Kaufman (1976), donde se demuestra con contundencia que los olmecas hablaron lenguas vinculadas al tronco $\mathrm{MZ}$, al menos en parte. Aparte de razones cronológicas y geográficas (el protoMZ y sus primeras fases evolutivas coinciden plenamente con la datación y localización arqueológicas asignada a los olmecas), existen diversas consideraciones lingüísticas como los préstamos, muchos de ellos términos típicos del área cultural mesoamericana, cuya presencia en grupos lingüisticos externos era hasta ahora dificilmente explicable. Uno de los más interesantes es cacao (ibid., p. 84): documentada en náhuatl, la palabra en cuestión no puede ser protouto-azteca puesto que la única lengua que la posee es el propio náhuatl, por otro lado en las lenguas mayas existe chol kakaw y tzotzil kokow, pero tal y como ocurriese con la forma náhuatl, ésta no puede ser maya, ya que viola la estructura silábica canónica y casi obligatoria de estas lenguas (ver la parte « Breve descripción del PM »). Campbell y Kaufman (ibid.) concluyen que su origen es, en efecto, protoMZ */kakaw/, cfr. totonaca kakaw, jicaque $k^{h} a w$, paya $k a k u$, huave kakaw, lenca kaw, tarascan kahékua. Una crítica constructiva de la labor realizada por 
Kaufman y Campbell es Dakin y Wichmann (2000), que abogan por el origen uto-azteca del término en cuestión.

29. Por cuestiones articulatorias, se prefiere la trascripción * $/ \mathrm{t}^{\prime y} / \mathrm{a}$ la de Campbell * $/ \mathrm{t}^{\mathrm{y}} \%$. Además, en un caso idéntico el propio Campbell opta por $* / \mathrm{k}^{* \mathrm{w}} /$, en vez de $* / \mathrm{k}^{\mathrm{w}} /$. A no ser que se especifique lo contrario, la opinión de Campell y/o Kaufman es la recogida en estas líneas.

30. Donde $\mathrm{C}=$ cualquier consonante, $\mathrm{V}=$ cualquier vocal, $\mathrm{S}=/ \mathrm{s} /,|\tilde{\mathrm{s}} /,| \mathrm{x} /$.

31. "The reconstruction of sound segments and syllable nuclei for a protolanguage is secondary to the establishment of sound correspondences across its daughter languages » (Wichmann y Brown 2004, p. 161). Sobre esta importantísima cuestión metodológica, véase Lakarra y Gorrochategui (2001), con bibliografia adicional.

32. La diferencia entre los « coeficientes sonánticos » de Saussure (ver nota 24) y el tercer rasgo propuesto por Wichmann y Brown es que los primeros quedaron refrendados (y ampliados) gracias al descubrimiento de una nueva lengua, el hitita, que demostraba material y, por lo tanto, filológicamente, su existencia, mientras que esta « nueva » cualidad vocálica PM no parece que vaya a ser refrendada por ninguna lengua aún no descubierta. Esto, por supuesto, no descarta que próximas investigaciones arrojen algo más de luz sobre el asunto, bien sea a través de modificaciones en la propia hipótesis, o bien con la inclusión de nuevos análisis materiales (Soren Wichmann, comunicación personal).

33. Esta ausencia no puede deberse a cuestiones ortográficas, puesto que como es bien sabido, la tradición de otras muchas lenguas, por ejemplo del náhuatl, ya había previsto la codificación del fonema $/ \mathrm{kw} /$.

34. Aunque la obra de Robertson (1992) es criticable en varios aspectos, sobre todo en lo que concierne a algunas decisiones de caracter metodológicos, p. ej. la seguridad con la que desacredita la posibilidad de identificar como retenciones protoch'olanas algunas marcas gramaticales que bien podrian adscribirse a una filiación dialectal de las inscripciones orientales (Mora-Marín 2005) o la condición del ch'olt'i como descendiente del ch'orti' (en contra Wichmann 2002), sigue siendo no sólo una delicia de lectura, sino toda una propuesta de análisis que debe ser lectura obligatoria para todo aquél que esté interesado en esta enrevesada cuestión.

35. Una lengua ergativa señala, p. ej. mediante desinencias, el origen de la acción verbal en enunciados con verbos transitivos e intransitivos. Este comportamiento se opone a lo que ocurre en lenguas acusativas, como p. ej. el latín, donde se señala el objeto al que va dirigida la acción verbal, no el orígen de ésta. Grosso modo, la naturaleza ergativa prefiere distinguir a quién o qué realiza la acción, mientras que las lenguas acusativas se concentran en la dirección, el resultado o el objeto hacia el que la acción va dirigida. En las lenguas acusativas, como las indoeuropeas, el sujeto no experimenta ningún tipo de caracterización, sino que es el objeto el elemento caracterizado. Véase Dixon (1994) como introducción indispensable al concepto de ergatividad. En el caso de las lenguas mayas, dichas desinencias están representadas por los índices personales. En yucateco existen dos inventarios, denominados tradicionalmente A y B, uno para el sistema acusativo y otro para el ergativo. Los componentes del primer inventario sirven además como marcas de posesión nominal.

36. La antipasiva es considerada una voz, como la activa o la pasiva, que dispone, como las aludidas, de autonomía morfológica. Así, los verbos transitivos distinguen en yucateco cuatro voces: activa, pasiva, media y antipasiva, p. ej. b'on (activa), b'ó? on (pasiva), b'óon (media) y b'òon (antipasiva) de una raiz con significado " pintar » (Reifler Bricker 1978).

37. Donde $\mathrm{V}=$ verbo, $\mathrm{O}=$ objeto, $\mathrm{S}=$ sujeto.

38. Campbell y Norman (1978) opinan que el orden sintáctico VSO tenía lugar cuando S y O eran idénticos en animicidad, cuando se introducía una oración subordinada, o cuando el $\mathrm{O}$ hacía referencia a una información ya suministrada, cediendo importancia al S, que se situaba por tanto más cerca del verbo.

39. Michael D. Coe (1992) presenta las vicisitudes del desciframiento de esta compleja escritura. Sin embargo, se escapa a la comprensión del lector avezado por qué Coe califica de « inadecuada » a la Unión Soviética de los años 1950, cuando la gran figura del desciframiento de los jeroglificos mayas fue el etnógrafo ucraniano Juri Valentinovič Knorozov (1922-1999), que consiguió los documentos 
necesarios para su estudio: el famoso compendio de 1933 que incluía los códices de Dresde, Madrid y París, tras salvarlos de la quema en la Biblioteca Nacional de Berlín, a donde había llegado como artillero del regimiento 58 durante la Segunda Guerra Mundial. Al mismo tiempo, otros colegas suyos se abrian paso con escrituras no menos misteriosas, como ocurriese con Vitalij Viktorovič Ševoroškin con el cario, que no sólo conseguiria leer, sino que incluso demostraria la relación de esa lengua con las indœuropeas anatolias (Sidwell 1995, p. 68; Coe 1991). El desciframiento completo de esta lengua seria realizado por Adiego (1993). Sea como fuere, IVichmann (2006a) ofrece una magnífica panorámica del estado actual de la epigrafia maya en combinación con la práctica de la lingüistica histórica. De gran importancia en ese trabajo son los actuales avances experimentados en el campo de la gramática maya jeroglifica, gracias a los cuales la traducción segura de muchas inscripciones es ya una realidad palmaria. Una aproximación física a los jeroglificos mayas con valor gramatical puede encontrarse en Stuart (2005, pp. 42-78).

40. Ya en 1979 Lyle Campbell (1984) afirmaba que la lengua de las inscripciones clásicas debia ser ch'olano, yucateco o tzeltal. Pese a estos primeros momentos dubitativos, lo reducido del ámbito taxonómico al que se reducian las posibilidades hacía prácticamente imposible errar en la identificación de la lengua. Ese mismo año y en esa misma conferencia, Kaufman y Norman (1984) presentaron las principales características de la lengua que usaron los portadores de la civilización clásica maya, aquellos que posteriormente la codificarian.

\section{REFERENCIAS BIBLIOGRÁFICAS}

ADIEGo Ignacio-Javier

1993 Studia carica: investigaciones sobre la escritura y lengua carias, PPU, Barcelona.

Aikhenvald Alexandra

2002 «Review of Lyle Campbell (1997) », Journal of Linguistics, 38, pp. 142-146.

BAUDEZ Claude-François

2002 «Venus y el Códice Grolier », Arqueología Mexicana, 10 (55), pp. 70-79.

Bouda Karl

1960 "Tungusisch und Ketschua », Zeitschrift der Deutschen Morgenländischen Gesellschaft, 110, pp. 99-113.

BRICKER Victoria

1986 A grammar of Mayan hieroglyphs, Tulane University, New Orleans.

\section{Campbell Lyle}

1978 "Quichean prehistory: linguistic contributions ", in Nora C. England (ed.),

Papers on Mayan linguistics, University of Missouri, Columbia, pp. 25-54.

1984 "The implications of Mayan historical linguistics for glyphic research ", in John S. Justenson y Lyle Campbell (eds), Phoneticism in Mayan hieroglyphic writing, Institute for Mesoamerican Studies, Albany, pp. 1-16

1988a The linguistics of southeastern Chiapas, Papers of the New World Archaeological Foundation, Provo.

1988 b "Review of Greenberg (1988) », Language, 64, pp. 591-615.

1990a "Philological studies and Mayan languages », in Jacek Fisiak (ed.), Historical linguistics and philology, Mouton de Gruyter, Berlin, pp. 87-105. 
1990b "Mayan languages and linguistic change », in Philip Baldi (ed.), Linguistic change and reconstruction methodology, Mouton de Gruyter, Berlin, pp. 115129.

1997a "Linguistic contributions to Guatemalan prehistory ", in Jane H. Hill, P. J. Mistry y Lyle Campbell (eds), The life of language. Papers in linguistics in honor of William Bright, Mouton de Gruyter, Berlin, pp. 183-192.

1997b American Indian languages. The historical linguistics of Native America, Oxford University Press, Oxford.

1999 Historical linguistics: an introduction, The MIT Press, Massachusetts.

2003 "On South American Indian languages. Reply to Aikhenvald », Journal of Linguistics, 39, pp. 141-145.

Campbell Lyle y Terrence Kaufman

1976 "A linguistic look at the Olmecs », American Antiquity, 41, pp. 80-89.

1985 "Mayan linguistics: where are we now », Annual Review Anthropology, 14, pp. 187-198.

\section{Campbell Lyle y William M. Norman}

1978 "Toward Proto-Mayan Syntax: A Comparative Perspective on Grammar ", in Nora C. England (ed.), Papers on Mayan linguistics, University of Missouri, Columbia, pp. 136-156.

Campbell Lyle, Pierre Ventur, Russell Stewart y Thomas Simth-Stark

1978 Bibliography of Mayan languages and linguistics, Institute for Mesoamerican Studies, New York.

Campiell Lyle, Terrence Kaufman y Thomas Smith-Stark

1986 «Mesoamerica as a linguistic area », Language, 62, pp. 530-570.

Cok Michael

1991 "A Triumph of Spirit », Archaeology, 44 (5), pp. 39-44.

1992 Breaking the Maya code, Thames and Hudson, New York.

Dakin Karen y Søren WichmanN

2000 "Cacao and chocolate: a Uto-Aztecan perspective ", Ancient Mesoamerica, 11, pp. 1-21.

Dixon Robert M. W.

1994 Ergativity, Cambridge University Press, Cambridge.

EDMONSON Munro S. (ed.)

1984 Linguistics, in Victoria Reifler Bricler (gen. ed.), Supplement to the Handbook of Middle American Indians, vol. 2, University of Texas Press, Austin.

ENGLAND Nora C.

1996 Introducción a la lingüística: idiomas mayas, Cholsamaj, Guatemala.

FrANKLE Eleanor

1984a "Las relaciones externas entre las lenguas mayaces y altaicas ", in XVII Mesa Redonda de la Sociedad Mexicana de Antropología, vol. 1, México, pp. 209-225. 
1984b «Los morfemas vocálicos para derivaciones verbales en los grupos mayance y túrquico ", in XVII Mesa Redonda de la Sociedad Mexicana de Antropología, vol. 2, México, pp. 517-524.

Georg Stefan, Peter Michalove, Alexis Manaster Ramer y Paul Sidivell

1998 "Telling general linguists about Altaic », Journal of Linguistics, 35, pp. 65 98.

GreenBerg Joseph H.

1987 Languages in the Americas, Stanford University Press, Stanford.

Haspelmath Martin, Matthew S. Dryer, David Gil y Bernard Comrie

2005 The world atlas of language structures, Oxford University Press, Oxford.

HeATH Shirley B.

1972 La política del lenguaje en México: de la colonia a la nación, Secretaría de Educación Pública e Instituto Nacional Indigenista, México.

Houston Stephen, John S. Robertson y David StuarT

2000 "The language of Classic Maya inscriptions », Current Anthropology, 41 (3), pp. 321-356.

HyMES Dell

1961 «Review of Tungusisch und Ketschua by Karl Bouda », International Journal of American Linguistics, 27, pp. 362-364.

1965 "The methods and tasks of anthropological philology (illustrated with Clackmas Chinnok) ", Romance Philology, 19, pp. 325-340.

KAUFMan Terrence

1976 «Archaeological and linguistic correlations in Mayaland and associated areas of Meso-America ", World Archaeology, 8, pp. 101-118.

Kaufman Terrence y William M. Norman

1984 "An outline of protoCholan phonology, morphology, and vocabulary ", in John S. Justenson y Lyle Campbell (eds), Phoneticism in Mayan hieroglyphic writing, Institute for Mesoamerican Studies, Albany, pp. 77-166.

KIRCHHOFF Paul

1943 «Mesoamérica », Acta Americana, 1, pp. 92-107.

LACADENA Alfonso

1997 "Bilingüismo en el Códice de Madrid », in Los investigadores de la cultura maya, Universidad Autónoma de Campeche, Campeche, pp. 184-204.

LAKARRa Joseba y Joaquim Gorrochategui

2001 "Comparación lingüistica, filología y reconstrucción del protovasco », in Francisco Villar y María Pilar Fernández Álvarez (eds), Religión, lengua y cultura prerromanas, Universidad de Salamanca, Salamanca, pp. 407-438.

LEDESMA Manuel

1996 El albanés. Gramática, historia, textos, Ediciones Clásicas, Madrid. 
MACLEOD Barbara

1984 «Cholan and Yucatecan verb morpohology and glyphic verbal affixes in the inscriptions ", in John S. Justenson y Lyle Campbell (eds), Phoneticism in Mayan hieroglyphic writing, Institute for Mesoamerican Studies, Albany, pp. 233-262.

1986 An epigrapher's annotated index to Cholan and Yucatecan verb morphology, University of Missouri, Columbia.

MAYERs Marvin K. (ed.)

1966 Languages of Guatemala, Mouton, London/The Hague/Paris.

McQuown Norman A.

1955 "The indigenous languages of Latin America », American Anthropologist, 57, pp. 501-567.

McQuown Norman A. (ed.)

1967 "Linguistics ", in Robert Wauchope (gen. ed.), Handbook of Middle American Indians, vol. 5, University of Texas Press, Austin.

Mora-Marín David

2005 «Proto-Ch'olan as the standard language of Classic Lowland Mayan texts », http://www.unc.edu/ davidmm/ProtoCholanHypothesis.pdf

Moreno Cabrera Juan Carlos

2003 El universo de las lenguas, Castalia, Madrid.

REIFLER BRICKER Victoria

1978 "Antipassive constructions in Yucatec Maya », in Nora C. England (ed.), Papers on Mayan linguistics, University of Missouri, Columbia, pp. 3-24.

ROBERTSON John S.

1977 "A proposed revision in Mayan subgrouping », International Journal of American Linguistics, 43 (2), pp. 105-120.

1992 The history of tenselaspect/mood/voice in the Mayan verbal complex, University of Texas Press, Austin.

Robertson John S. y Stephen Houston

2003 "El problema del wasteko: una perspectiva lingüística y arqueológica », in Juan Pedro Laporte, Héctor L. Escobedo y Barbara Arroyo (eds), XVI Simposio de Investigaciones Arqueológicas en Guatemala, vol. 2, Museo Nacional de Arqueología y Etnología, Ciudad de Guatemala, pp. 723-733.

Ruz LhuilLier Alberto

1989 Los antiguos mayas, Fondo de Cultura Económica, México [1981].

SCHELE Linda

1982 Maya glyphs. The verbs, University of Texas Press, Austin.

Sidwell Paul

1995 «Review of Michacl D. Coe (1992) », Dhumbadji!, 2 (2), pp. 66-68.

Stolz Thomas

2002 "No Sprachbund beyond this line! On the age-old discussion of how to define a linguistic area », in Paolo Ramat y Thomas Stolz (eds), Mediterra- 
nean languages: papers from the MEDTYP workshop, Tirrenia, June 2000, Brockmeyer, Bochum, pp. 259-281.

Stuart David

2005 Sourcebook for the 29th Maya hieroglyph forum, March 11-16, 2005, University of Texas, department of Art and Art History, Austin.

Tuite Kevin

1999 "The myth of the Caucasian Sprachbund: the case of ergativity ", Lingua, 108 (1), pp. 1-29.

VILLAR Francisco

1996 Los indoeuropeos y los origenes de Europa, Gredos, Madrid.

\section{WiCHMANN Søren}

2002 Hieroglyphic evidence for the historical configuration of Eastern Ch'olan, Center for Maya Research, Washington DC.

2006a "Mayan historical linguistics and epigraphy: a new synthesis ", Annual Review of Anthropology, 35, pp. 279-294.

2006b "Un panorama de las lenguas indigenas de México », in Robert de Jonge (ed.), Las lenguas de México, Gröningen University, Gröningen [en prensa].

Wichmann Søren y Cecil H. Brown

2003 " Contact among Some Mayan Languages. Inferences from Loanwords », Anthropological Linguistics, 45 (1), pp. 57-93.

2004 «Proto-Mayan syllable nuclei », International Journal of American Linguistics, 70 (2), pp. 128-186.

WIKANDER Stig

1967 " Maya and Altaic I », Ethmos, 32, pp. 141-148.

1970 "Maya and Altaic II ", Ethnos, 35, pp. 80-88.

1970-1971 « Maya and Altaic III », Orientalia Suecana, 19-20, pp. 186-204.

WINTER Werner (ed.)

1960 Evidence for laryngeals, The University of Texas, Texas.

YASUGI Yoshiho

1995 Native Middle American languages. An areal-typological perspective, National Museum of Ethnology, Osaka.

Zimmerman Klaus (ed.)

1997 La descripción de las lenguas amerindias en la época colonial, Instituto Ibero-Americano, Frankfurt am Main. 